\title{
Dietary Supplement Use in Sport Gyms in Lebanon: Are They Necessary and are There Side-Effects?
}

\author{
Ali Salami ${ }^{1, "}$ Ali Ghaddar, ${ }^{2,3}$ Eleonore Aboumrad, ${ }^{4}$ and Wissam H. Joumaa ${ }^{5}$ \\ ${ }^{1}$ Department of Mathematics, Faculty of Sciences, Lebanese University, Nabatieh, Lebanon \\ ${ }^{2}$ Lebanese International University, Faculty of Arts and Sciences, Msaitbeh, 14- 6404, Beirut, Lebanon \\ ${ }^{3}$ Observatory of Public Policies and Health, Bonmarche Center, Beirut, Lebanon \\ ${ }^{4}$ Department of Nutrition, Faculty of Sciences, Lebanese University, Beirut, Lebanon \\ ${ }^{5}$ Environmental Physio-Toxicity Laboratory (PhyToxE), Faculty of Sciences, Lebanese University, Nabatieh, Lebanon \\ "Corresponding author: Ali Salami, Department of Mathematics, Faculty of Sciences, Lebanese University, Nabatieh, Lebanon. Tel: +96-170235206, Tel/Fax: +96-17260103, E-mail: \\ salami.ali@hotmail.com
}

Received 2015 September 21; Revised 2016 January 24; Accepted 2016 March 01.

\begin{abstract}
Background: The use of dietary supplements is very common in sport gyms worldwide. However, their use in exercisers in Lebanese gyms has never been investigated.

Objectives: The study aim was to evaluate the dietary intake of food macronutrients and to explore any side-effects associated with this kind of consumption.

Patients and Methods: Three hundred and sixty exercisers aged 20 - 50 years were randomly selected for participation in this crosssectional study. The majority were men (60\%) aged 20 - 30 years (78\%).

Results: The intake of dietary supplements was observed in $38 \%$ of the study participants, with the highest prevalence in men (73\%). It was also found that daily protein intake exceeded dietary needs in $92 \%$ of the participants, while daily fat intake was less than that required in $76 \%$ of them. It was noteworthy that $63 \%$ of supplement users in this study reported having experienced between one and several side-effects.

Conclusions: These results indicate a lack of awareness among people who exercise regularly on the benefits and side-effects of dietary supplements. There is an urgent need for the implementation of campaigns that target gym users in Lebanon to raise awareness in this regard.
\end{abstract}

Keywords: Adverse Effects, Dietary Habits, Dietary Supplements, Lebanon

\section{Background}

A high prevalence of dietary supplement use can be observed worldwide in gym users, varying from $37 \%$ in Brazil (1) to $85 \%$ in the USA (2). However, there is limited information in this regard in gyms in the Middle East and North Africa region (3).

It has been shown in recent studies that people who exercise used dietary supplements to enhance bodily appearance, muscle gain, strength, and physical performance (4). Users believe that dietary supplements facilitate their ability to cope with training requirements, while enhancing competitive performance (5). Kristiansen reported that female athletes use supplements for general health benefits, whereas male athletes do so mostly to improve performance and to increase strength (6). Despite the fact that the health risks associated with the use of dietary supplements are still under-investigated, it has been indicated in previous research that they are associated with many adverse health consequences. It was shown in a review that although creatine may be marginally beneficial, any associated potential benefit is probably only useful to a professional athlete and not the average person (7). It was concluded in the same review that protein and amino acid supplements and ephedra-containing dietary supplements potentially have harmful side-effects (7). Furthermore, the progressive use of protein-calorie supplementation was discouraged in a study in Brazil because of its association with the onset of acne within a two-month period (8).

Dietary supplements containing ephedrine and pseudoephedrine have detrimental cardiovascular effects. Erythropoietin increases the risk of thromboembolic events. Androstenedione and dehydroepiandrosterone have potentially significant adverse effects, and anabolic steroids have many, some of which are irreversible (9). However, gender-related differences in relation to the adverse effects that are associated with the consumption of dietary supplements have not previously been described.

It has been suggested that gyms users rely on athletic trainers as a primary source of nutrition information and rarely on dietitians (10). Unfortunately, most coaches and athletes have inadequate knowledge of sport nutri- 
tion and recommend the consumption of dietary supplements (11). Although people who are engaged in sports obtain sufficient nutrients from a balanced diet and thus do not require dietary supplements, the amount and pattern of macronutrient and energy intake in the daily diet in gym users who consume dietary supplements has not yet been studied.

\section{Objectives}

The purpose of this study was to describe the patterns of dietary supplement use in gym users in Lebanon, to assess their dietary macronutrient intake, and to explore the side-effects associated with the consumption of dietary supplements.

\section{Patients and Methods}

\subsection{Participants}

A cross-sectional study was carried out in Lebanon from April 2014 to June 2014. Gyms in one region of Lebanon (Mount Lebanon) were identified according to the address listings provided in the telephone directory. A stratified random sample of 30 gyms was selected from a total of nine cities in the region where the study was conducted. The number of gyms from each city was selected in proportion to the population size of each city. Only individuals aged 20 - 50 years were included in the study, with no regard for sex or socio-economic status.

Of a total of 360 participants who were recruited using stratified random sampling and who completed the questionnaire, only 144 subjects agreed to submit to a nutritional assessment by a dietitian.

The participants signed a formal consent form after being informed about the study objectives. The study was conducted according to the principles contained in the world medical association Helsinki declaration and was approved by the institutional review board of the Lebanese University of Beirut, Lebanon (ethical approval reference number 097/14).

\subsection{Measurements}

A nutritional assessment (three-day food diary) of the food content and the contribution of dietary supplements was performed by a dietitian. The three-day food diary comprised three sections in which participants were asked to record the consumption of foods, beverages, and dietary supplements, as well as the time and conditions surrounding food consumption. Participants were asked to select three representative days (two training days and one rest day) for the purposes of recording their dietary consumption. To improve the accuracy and representativeness of the results, a detailed explanation of the procedures and visual examples of the portions were given to the participants. The validity and representativeness of this tool in the evaluation of dietary intake is well documented (12). The food diaries were analyzed in two phases using Food Smart@ software (version 5.0). The nutritional intake of food, with the exclusion of dietary supplements, was considered in the first analysis. The second analysis was of the contribution made by the dietary supplements.

Participants were asked to make note of any sideeffects experienced during the last three months following the use of dietary supplements. The responses were grouped into four categories of polyuria, mood swings, hypertension, and excess facial hair. Hypertension was measured using the standard method (a sphygmomanometer) before the participants commenced exercising.

\subsection{Statistical Analysis}

Statistical analysis was conducted using SPSS 20 . The level of significance was set at $\mathrm{P}$ value $\leq 0.05$. Logistic regression was used to determine any association between the side-effects ("yes"|"no") as a dependent variable and supplement use as an independent variable. Four separate multiple regression models were applied as dependent measures of the side-effects of polyuria, mood swings, hypertension, and excess facial hair.

\section{Results}

\subsection{Demographic Characteristics}

The majority of the participants were men (60\%). A high percentage of the study subjects were aged $20-30$ years (78\%) and (60\%) had a university degree. Most of them (66\%) exercised regularly, e.g., 3 - 5 times a week, and 66\% did so for 1 - 2 hours per day. Forty-four per cent of the participants had been exercising for $\geq 1$ year.

\subsection{Dietary Supplement Side-Effects}

The most frequently reported side-effects with regard to supplement use were polyuria (29\%), hypertension (18\%), excess facial hair (12\%), and mood swings (4\%). More than half of the participants (63\%) reported experiencing one of these side-effects. The results of the logistic regression analysis are shown in Table 1. In general, dietary supplement use was positively associated with hypertension $(\beta$ $=2.01, \mathrm{P}=0.228)$, excess facial hair $(\beta=5.31, \mathrm{P}=0.036)$, and polyuria $(\beta=2.12, \mathrm{P}=0.006)$. Being a man was positively associated with polyuria $(\beta=0.263, \mathrm{P}=0.021)$, hypertension ( $\beta=0.431, \mathrm{P}=0.327)$, and mood swings $(\beta=0.545, \mathrm{P}=0.047)$ 
but was negatively associated with excess facial hair ( $\beta=$ $1.889, \mathrm{P}=0.641)$. It was also found that the association between supplement use and the development of polyuria $(\beta$ $=1.43, \mathrm{P}=0.077)$, mood swings $\beta=1.73, \mathrm{P}=0.648$ ), and hypertension ( $\beta=1.68, \mathrm{P}=0.667)$ increased with age as those aged 40 - 50 years were at highest risk in this regard by comparison with those in the reference age group (of 20 - 30 years). In addition, it was found that excess facial hair decreased with advancing age, e.g., in those aged 40 - 50 years $)(\beta=0.29, \mathrm{P}=0.422)$.

\subsection{Average Daily Intake of Macronutrients}

An analysis of dietary intake was separately conducted with respect to users $(n=63)$ and non-users $(n=81)$ of dietary supplements. The percentage of carbohydrate, protein, and fat intake in relation to total dietary intake was determined by the dietitian. A comparison was made between the results and the recommended dietary allowance (RDA) (Table 2) $(13,14)$.

The total energy intake in dietary supplement users ranged from 875 - $6530 \mathrm{kcal} /$ day (an average of 2375 $\mathrm{kcal} /$ day), representing $95 \%$ of the recommended daily intake of energy for an athlete of $2500 \mathrm{kcal} /$ day. Furthermore, $62 \%$ of the participants consumed a diet with energy intake that was inferior to that in the recommendations, while $19 \%$ of the subjects consumed a diet with energy content that exceeded that in the recommendations.

It is noteworthy that a carbohydrate intake below the RDA was recorded in the majority of users (68\%) and nonusers (63\%) of dietary supplements. Seventy-five per cent of both users and non-users of dietary supplements consumed 53\% of carbohydrates (Q3). The majority of users and non-users of dietary supplements consumed more than the RDA for protein (92\% for users versus $100 \%$ for non-users). Users of dietary supplements consumed more protein $(\mathrm{Q} 3=60 \%)$ than non-users $(\mathrm{Q} 3=9 \%)$. The opposite trend was noticed for fat intake, with $76 \%$ of users having an intake below, and 72\% of non-users having an intake above, the RDA (Table 2).

\section{Discussion}

The high consumption of dietary supplements can be attributed to the fact that in general, athletes are unaware that supplements can have a negative impact on health (15). More than half of the dietary supplement users in this study (63\%) reported experiencing one or several sideeffects; a finding that supports that in previous research on the side-effects of dietary supplements (16).

An important difference concerning gender and age was depicted in this study with regard to these side-effects.
The higher identified risk of polyuria, mood swings, and hypertension in men might be attributed to the fact that they tend to train more intensively and to consume a greater amount of protein than women. Excess facial hair was more commonly seen in female than in male users of dietary supplements. This might be due to the hormonal changes that are commonly observed in women. It was shown in the current study that as age increased, so did the risk of polyuria, hypertension, and mood swings. Further studies involving a larger sample size need to be conducted to better explore the side-effects of dietary supplements in older persons.

A unique aspect of the current study was that a nutritional assessment was undertaken of the food intake of gym users who consumed dietary supplements. It was found that the protein intake of most of the gym users exceeded their needs. The association between excessive protein intake and a healthy body mass index has not been scientifically proven (17). Although protein synthesis is essential for several body structures and proteins are involved in many metabolic mechanisms, their intake is not enough to increase body mass and strength without the parallel use of an exercise regimen. Moreover, caloric intake is essential to achieve a positive protein balance in the skeletal muscle of subjects engaged in resistance training (18). It has been suggested that athletes need extra protein in their diet as food or supplements (18), but individuals who regularly exercise in gyms do not require extra protein. Furthermore, the excessive intake of protein as food or as a supplement seems to be associated with side-effects such as ketosis, gout, kidney overload, increased body fat, dehydration, the urinary excretion of calcium, and loss of bone mass (19). Finally, a daily fat intake below the recommended amount required to meet dietary needs was observed in the majority of participants in our study. This can be attributed to the misconception that fat is harmful to health and that its consumption results in people gaining weight, rather than muscle mass.

\subsection{Conclusions}

It is crucial that governmental and non-governmental organizations launch several awareness campaigns to highlight the dangers associated with the use of dietary supplements in sports.

\section{Acknowledgments}

The authors thank the gyms and study participants for their cooperation. 
Salami A et al.

Table 1. Results of the Logistic Regression Analysis, With the Side-Effects as Dependent Variables

\begin{tabular}{|c|c|c|c|c|c|c|c|c|}
\hline \multirow[t]{2}{*}{ Independent Variables } & \multicolumn{2}{|c|}{ Polyuria } & \multicolumn{2}{|c|}{ Mood Swings } & \multicolumn{2}{|c|}{ Hypertension } & \multicolumn{2}{|c|}{ Excess Facial Hair } \\
\hline & $\operatorname{Exp}(B)$ & 95\% CI & $\operatorname{Exp}(B)$ & 95\% CI & $\operatorname{Exp}(B)$ & 95\% CI & $\operatorname{Exp}(B)$ & 95\% CI \\
\hline \multicolumn{9}{|l|}{$\operatorname{Sex}^{\mathrm{a}}$} \\
\hline Women & 0.26 & $0.06-1.26$ & 0.55 & $0.11-2.73$ & 0.43 & $0.04-3.22$ & 1.89 & $0.16-22.02$ \\
\hline \multicolumn{9}{|l|}{ Dietary supplement use } \\
\hline User & 2.12 & $0.65-6.92$ & 1.03 & $0.41-2.60$ & 2.02 & $0.66-6.29$ & 5.31 & $1.11-25.32$ \\
\hline \multicolumn{9}{|l|}{ Age, $y$} \\
\hline $30-40$ & 1.36 & $0.26-6.98$ & 1.75 & $0.21-14.98$ & 1.16 & $0.13-10.40$ & 0.96 & $0.10-9.47$ \\
\hline $40-50$ & 1.4 & $0.23-8.85$ & 1.73 & $0.17-18.16$ & 1.68 & $0.16-18.07$ & 0.29 & $0.01-5.90$ \\
\hline
\end{tabular}

Abbreviarion: CI, confidence interval, $\operatorname{Exp}(\mathrm{B})$.

${ }^{\mathrm{a}}$ The reference group was men, who were non-users of dietary supplements and aged 20 - 30 years.

Table 2. Daily Macronutrient Intake in Users and Non-Users of Dietary Supplements

\begin{tabular}{|c|c|c|c|c|}
\hline Daily Macronutrient Intake & Energy, kcal/d & Carbohydrates, \% & Protein, \% & Fat, \% \\
\hline \multirow{6}{*}{ Users of dietary supplements $(n=63)$} & $\mathrm{ADDI}=2375$ & $\mathrm{RDA}=50-60$ & $\mathrm{RDA}=10-15$ & $\mathrm{RDA}=20-25$ \\
\hline & Range $=875-6530$ & \% below $\mathrm{RDA}=68.3$ & \% below $\mathrm{RDA}=2.0$ & $\%$ below $\mathrm{RDA}=76.2$ \\
\hline & $\mathrm{PRPD}=95 \%$ & $\%$ above $\mathrm{RDA}=4.8$ & $\%$ above $\mathrm{RDA}=92.1$ & \% above $\mathrm{RDA}=12.7$ \\
\hline & $\%$ below needs $=61.9$ & $\mathrm{Q} 1=30.0$ & $\mathrm{Q} 1=27.0$ & $\mathrm{Q} 1=10.0$ \\
\hline & $\%$ above needs $=19.0$ & $\mathrm{Q} 2=44.0$ & $\mathrm{Q} 2=40.0$ & $\mathrm{Q} 2=16.0$ \\
\hline & & $\mathrm{Q} 3=52.5$ & $\mathrm{Q} 3=60.0$ & $\mathrm{Q} 3=20.5$ \\
\hline \multirow{6}{*}{ Non-users of dietary supplements $(\mathbf{n}=\mathbf{8 1})$} & $\mathrm{ADDI}=1907$ & $\mathrm{RDA}=50-60$ & $\mathrm{RDA}=10-15$ & $\mathrm{RDA}=20-25$ \\
\hline & Range $=1055-4000$ & $\%$ below $\mathrm{RDA}=63.0$ & $\%$ below $\mathrm{RDA}=0.0$ & \% below $\mathrm{RDA}=9.9$ \\
\hline & $\mathrm{PRPD}=76.3 \%$ & \% above RDA = 3.7 & $\%$ above $\mathrm{RDA}=100.0$ & $\%$ above $\mathrm{RDA}=71.6$ \\
\hline & $\%$ below needs $=85.2$ & $\mathrm{Q} 1=41.1$ & $\mathrm{Q} 1=20.2$ & $\mathrm{Q} 1=24.9$ \\
\hline & $\%$ above needs $=4.9$ & $\mathrm{Q} 2=47.0$ & $\mathrm{Q} 2=25.6$ & $\mathrm{Q} 2=29.0$ \\
\hline & & $\mathrm{Q} 3=52.7$ & Q3 $=29.4$ & $\mathrm{Q} 3=30.9$ \\
\hline
\end{tabular}

Abbreviarions: ADDI, average daily dietary intake; PRPD, percentage of recommended intake per day; RDA, recommended dietary allowance.

\section{Footnote}

Authors' Contribution: Ali Salami conceived the study idea, participated in the study design, coordinated the study, and was responsible for the statistical analysis and drafting the manuscript. Ali Ghaddar participated in the study design, statistical analysis, and in drafting the manuscript. Eleonore Aboumrad was responsible for collecting the data, evaluating the nutritional content of foods, and measuring the contribution of the dietary supplements. Wissam H. Joumaa participated in the study design and coordinated the study. All authors read and approved the final manuscript.

\section{References}

1. Goston JL, Correia MI. Intake of nutritional supplements among people exercising in gyms and influencing factors. Nutrition. 2010;26(6):604-11. doi: 10.1016/j.nut.2009.06.021. [PubMed: 20004078].

2. Morrison LJ, Gizis F, Shorter B. Prevalent use of dietary supplements among people who exercise at a commercial gym. Int JSport Nutr Exerc Metab. 2004;14(4):481-92. [PubMed: 15467105].

3. El Khoury D, Antoine-Jonville S. Intake of Nutritional Supplements among People Exercising in Gyms in Beirut City. $J$ Nutr Metab. 2012;2012:703490. doi: 10.1155/2012/703490. [PubMed: 22506105].

4. Nieper A. Nutritional supplement practices in UK junior national track and field athletes. Br J Sports Med. 2005;39(9):645-9. doi: 10.1136/bjsm.2004.015842. [PubMed: 16118303].

5. Krumbach CJ, Ellis DR, Driskell JA. A report of vitamin and mineral supplement use among university athletes in a division I institution. Int J Sport Nutr. 1999;9(4):416-25. [PubMed: 10660872].

6. Kristiansen M. Dietary supplement use by varsity athletes attending a Western Canadian university. Copenhagen: he Royal Veterinary and Agricultural University; 2004. 
7. Lawrence ME, Kirby DF. Nutrition and sports supplements: fact or fiction. J Clin Gastroenterol. 2002;35(4):299-306. [PubMed: 12352292].

8. Pontes Tde C, Fernandes Filho GM, Trindade Ade S, Sobral Filho JF. Incidence of acne vulgaris in young adult users of protein-calorie supplements in the city of Joao Pessoa-PB. An Bras Dermatol. 2013;88(6):90712. doi: 10.1590/abd1806-4841.20132024. [PubMed: 24474098].

9. Juhn MS. Popular sports supplements and ergogenic aids. Sports Med 2003;33(12):921-39.

10. Burns RD, Schiller MR, Merrick MA, Wolf KN. Intercollegiate student athlete use of nutritional supplements and the role of athletic trainers and dietitians in nutrition counseling. J Am Diet Assoc. 2004;104(2):246-9. doi: 10.1016/j.jada.2003.11.013. [PubMed: 14760575].

11. Torres-McGehee TM, Pritchett KL, Zippel D, Minton DM, Cellamare A, Sibilia M. Sports nutrition knowledge among collegiate athletes, coaches, athletic trainers, and strength and conditioning specialists. J Athl Train. 2012;47(2):205-11. [PubMed: 22488287].

12. Rutishauser IHE. Dietary intake measurements. Public Health Nutr. 2005;8(7a):1100-7.

13. American Dietetic Association . Dietitians of Canada, and American College of Sports Medicine (2000). Nutrition and athletic perfor- mance.; 2000 .

14. Burke L, Deakin V. Clinical sports nutrition. McGraw-Hill Book Company Australia Pty Ltd; 1994.

15. Tian HH, Ong WS, Tan CL. Nutritional supplement use among university athletes in Singapore. Singapore Med J. 2009;50(2):165-72. [PubMed: 19296032].

16. Momaya A, Fawal M, Estes R. Performance-enhancing substances in sports: a review of the literature. Sports Med. 2015;45(4):517-31. doi: 10.1007/s40279-015-0308-9. [PubMed: 25663250].

17. Duellman MC, Lukaszuk JM, Prawitz AD, Brandenburg JP. Protein supplement users among high school athletes have misconceptions about effectiveness. J Strength Cond Res. 2008;22(4):1124-9. doi: 10.1519/JSC.0b013e31817394b9. [PubMed: 18545198].

18. Campbell B, Kreider RB, Ziegenfuss T, La Bounty P, Roberts M, Burke D, et al. International Society of Sports Nutrition position stand: protein and exercise. J Int Soc Sports Nutr. 2007;4:8. doi: 10.1186/1550-2783-4-8. [PubMed: 17908291].

19. Tarnopolsky M. In: Clinical Sports Nutrition. Burke LM, editor. Sydney: McGraw-Hill; 2006. pp. 73-111.Protein and amino acid needs for training and bulking up. 